\title{
A conversation with Cornelia Bargmann
}

$\mathbf{H}_{\mathrm{o}}$ ow are behavioral decisions modified by context and experience? Cornelia Bargmann of Rockefeller University has made this her life's work, exploring the intersection between genes, the environment, and the nervous system in the roundworm, C. elegans. Bargmann (Figure 1) is also seeking to help cure, manage, and prevent all disease by the year 2100 by serving as Head of Science for the Chan Zuckerberg Initiative. Watch the full interview at www.jci. org/videos/cgms to hear her tell the story of how blowing up a toilet got her interested in science and what she finds most interesting about studying 37 trillion cells all at once.

JCI: What were you like as a child?

Bargmann: I grew up third of four sisters. My parents were immigrants from Europe, and like many immigrants, what they believed in was education. It was a very scholarly household full of books: we all played the piano, we all read. There was art, literature, math. My sisters all went to college, which was somewhat unusual in the town that I grew up in; in Athens, Georgia at the time, maybe only $20 \%$ of students went to college after high school. My father was in the Department of Statistics and Computer Science at the University of Georgia and before that, he had been at IBM in the early days of computing at the Watson Research Center.

I remember that whenever we would toast glasses around the dining room table, we had to calculate how many times the glasses were going to clink. I still look around a room and think, "Hmm, 6 times 5 divided by 2." These kinds of games were part of the vocabulary of the house, and part of understanding that whatever you learned whether it was about math or music - would be something that would apply in life.

JCI: When did you start to think seriously about science?

Bargmann: I grew up in the 1960s during the space era. And if you talk to scientists from that generation, we all wanted to be astronauts. At some point, I realized that being an astronaut was not practical, since I got sick every time I got on an airplane.

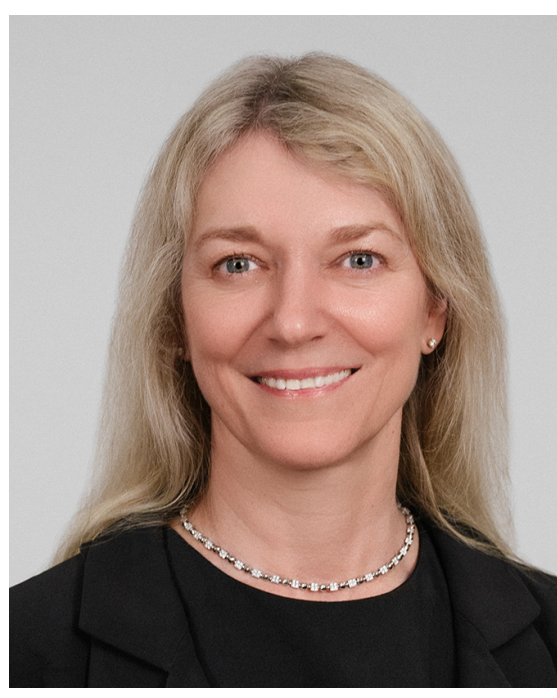

Figure 1. Cornelia Bargmann on May 15, 2018 in New York. Image credit: Alexey Levchenko.

Then my sister Eve went to medical school. I worshipped my older sister, so I decided I was going to be a doctor too. When I was 12 years old, I signed up to be a volunteer at the hospital to learn to be a doctor. I lasted two days. It was so upsetting to be with people in need and not be able to help them. But that idea led me to science. Not long after that, I started working in a chemistry lab, and then a biology lab. The combination of the lab being very much about learning and also immediate and concrete - you work with your hands, you spend all day talking with smart people - was incredibly compelling.

I was not a natural. The way I remember my first summer in the lab as an undergraduate is that every day I would plate out bacteria, and then go home. The next morning I would come in and the experiment would have failed. I would go to the vending machine and eat some Twinkies, and then go back in and do the experiment again. There was something about eventually getting it to work that was such a thrill. The potential that molecular biology opened up in understanding biological problems in a new way was obvious even to a college student, and the excitement of being able to learn new things using new approaches was what drew me into genetics.
JCI: How did you decide to go work on oncogenes with Bob Weinberg for your $\mathrm{PhD}$ ?

Bargmann: I joined the Weinberg lab right at the time that the lab discovered that changes in the Ras genes were associated with the transforming ability of human tumors. In my first summer, the lab identified the exact molecular change at Ras amino acid 12 that occurred in tumor cells. This was work done by graduate students - Cliff Tabin and Luis Parada. It was an easy decision for a graduate student to go there!

The early work on oncogenes led to incredible discoveries, and yet at the time, it didn't feel like we were in control of this huge problem. We were graduate students trying to make things work, and most of the time they didn't, and we dropped things on the floor and contaminated our cultures. Somehow, we kept at it and these discoveries happened.

I feel really proud to be part of what the lab accomplished at that time. My project was to clone a gene that was associated with rat neuro- and glioblastomas. Most of the people in the lab were working on human tumors, but there were reasons to think that these tumors were interesting. One reason was that sometimes the immune system attacked the transformed cells and the tumors spontaneously regressed. Ultimately several of us were able to identify the gene that was altered in those tumors. It turned out that the reason that the tumors regressed is that the gene, neu, encoded a transmembrane protein, a growth factor receptor. It was accessible on the surface of the cell and could be recognized by antibodies that would ultimately lead to its destruction. After that discovery was made, Genentech developed an antibody (Herceptin) that could be used to attack the transmembrane protein to target a class of human breast cancer in which this gene is altered.

JCI: Why did you turn from such an exciting discovery toward studying neuroscience in roundworms?

Bargmann: I had always been interested in neuroscience and particularly behavior. What became clear to me in graduate school was that the molecular approaches that we were using in cancer might also be applicable to problems in the brain and nervous system. 
At that time, a lot of people argued there couldn't possibly be genes that regulate behavior. This was despite the fact that the existence of innate behaviors implies that if there's something invariant in every individual in a species, it is probably encoded in the genome. But still, how that might work was a real puzzle. I came to $C$. elegans because it had great genetics. Also, I was interested in behavior and genetics, but it was clear that there was going to be a nervous system between point A and point B. Right then, a connectivity map of the C. elegans nervous system was published that would serve as a way to move back and forth between what molecules, neurons, and the organism did. That wiring diagram is still the foundation of what goes on in my lab every day.

One of the things I've learned about studying behavior is that you're doing yourself a big favor if you study something that the animal wants to do. To the extent that you can use an animal in a setting that it finds interesting and engaging and motivating, you will learn more. My postdoctoral advisor, Bob Horvitz, said that it was my greatness as a scientist that I could think like a worm. And worms care about smell. Their main way of interacting with the world is by detecting chemicals that are released by other organisms in their environment. The fact that they want to respond to chemicals, taste and smell their world and make behavioral decisions based on that, was a great reason to use that sense to study their behavior. At that point, smell and taste were really fun problems because we didn't know how they worked in any animal. And so it was a question for the worm, but it was a question in neuroscience more broadly: how you can detect different odors and tell them apart, how do you know what it good and what is bad, and how is that information acquired and processed by the nervous system?

JCI: What was it like to start your own lab at UCSF?

Bargmann: The fact is, I didn't really know that much about the brain when I started my own lab. When I went to UCSF I was hired into the Anatomy Department. It was really brave of them to decide that someone who was working on a very basic system on a then-obscure organism would be a good person to hire. It was also brave of them to hire me to work on the nervous system when I knew a lot about genes and molecules and worms at that point, but not so much about neurons.
UCSF had a fantastic interdepartmental neuroscience program, and that was the place that I learned about brains and how neural systems work. You just never know: you're starting out, you're an Assistant Professor, you're trying to set up your lab, you're trying to figure out how much ice buckets cost. The Assistant Professor in the lab next door was going through the same thing. He knew a ton about neuroscience, and we were interested in similar things. That was Marc Tessier-Lavigne, who went on to become one of the great developmental neuroscientists, the President of Rockefeller University, and now the President of Stanford University. I had the great experience of having a colleague who, at the time, seemed just as clueless as I was but was smart and thoughtful and stimulating, and helped my lab advance in its science. And I think our lab helped his lab advance its science as well.

JCI: After 14 years at UCSF, you transitioned to Rockefeller University.

Bargmann: Being at UCSF was fantastic. It was a great place to learn. But being at a state medical school is controlled chaos. The medical school was running hospitals, educating medical and pharmacy students, merging with Stanford, un-merging with Stanford, negotiating managed care, and there was research going on at the same time. The transition to Rockefeller happened at a time that I wanted to focus, and at Rockefeller the only thing that mattered was to try to move the frontiers of our fields forward through research. It was the right move at the right time.

JCI: With the way you describe your enthusiasm about scientific discovery, why did you start taking on administrative roles, such as the co-chair of the planning committee for the Obama-initiated BRAIN Initiative and now Head of Science for the Chan Zuckerberg Initiative?

Bargmann: When I first moved to UCSF, Bruce Alberts said, "With new resources, you can do new things. You have to seize the opportunity." Why Francis Collins asked me to do the BRAIN Initiative, you will have to ask him. But the BRAIN initiative was a unique opportunity for the neuroscience community. The BRAIN Initiative work was an intellectual effort, not an administrative one. I loved thinking through the next steps of neuroscience with my colleagues.

With regard to the Chan Zuckerberg Initiative: Mark Zuckerberg and Priscilla Chan decided on the birth of their first child that they were going to give away their wealth to try to make the world that their children live in better. Priscilla is a pediatrician and was very motivated by seeing children that she could not help. That led to the Chan Zuckerberg Initiative's mission to support science and technology to help cure, prevent, or manage all diseases by the end of the century. This mission is a lot to wrap your head around, but: One, the end of the century is a long way away. Two, science is powerful. Three, this is a community effort. The Chan Zuckerberg Initiative is not going to be the one group that solves all diseases. What we can do is think about where we might be able to make a differentiated impact with new resources. How can we accelerate progress? How can we make science better? Mark and Priscilla are in Silicon Valley, which has new perspectives on making systems more efficient through software engineering, data science, and rapid transmission of information between people. A lot of that technology hasn't moved back into science from the commercial sector, but these tools can make everyone smarter, faster. It's an incredibly generous gift, and an amazing opportunity.

We chose the Human Cell Atlas project as a first project for the Chan Zuckerberg Initiative because it is a perfect example of accelerating science broadly by building technology. Every human disease has a cellular basis - either cells are doing something they're not supposed to do, or they're not doing something they're supposed to do. But we don't actually know what each cell does. In fact, we don't even know how many different types of cells there are in the human body. Thousands? Tens of thousands? Millions? The Human Cell Atlas is setting out to learn how many cell types there are, how many of each, where they are, who their neighbors are, and what their molecular composition is - the RNAs and proteins in each cell type. Knowing this will serve as a foundation for studying every human disease.

JCI: If you were not a scientist, what else do you think would have captivated you?

Bargmann: I love being a scientist. The only thing I can come up with is being another kind of scientist. I love neuroscience. What could be a more fascinating problem than understanding the human brain?

\section{Ushma S. Neill}

